\title{
Morphometric Changes in Jejunal Mucosa in HIV Positive Patients Presenting with Enteropathy: An Indian study
}

\author{
Dibyajyoti Boruah $^{1 *}$, Jasvinder K Bhatia ${ }^{1}$, K D Kamal ${ }^{2}$ and Ajay Malik ${ }^{3}$ \\ ${ }^{1}$ Department of Pathology, Armed Forces Medical College, Pune-Maharashtra, INDIA. \\ ${ }^{2}$ Department of Internal Medicine, Armed Forces Medical College, Pune, Maharashtra, INDIA. \\ ${ }^{3}$ Department of Pathology, Army College of Medical Sciences, New Delhi, INDIA.
}

\begin{abstract}
Aims: Villous length, villous area, villous separation, villous tortuosity and crypt depth were evaluated in thejejunal mucosa of HIV positive cases with chronic diarrhea and correlated with controls and CD4 counts.

Methods: Endoscopic biopsies of jejunal mucosa from 30 confirmed HIV positive cases with enteropathy and 21 HIV negative controls were used.Villous parameters were assessed by computerized digital image morphometry on hematoxylin-eosin-stained histological sections.

Results: There were no significant differences in the mean villous length( $\mathrm{p}=0.9858$, case: $269 \mu \mathrm{m}$, control:270 $\mu \mathrm{m})$ and villous area $(\mathrm{p}=0.0610$, cases:30905 $\mu \mathrm{m} 2$, controls: $25864 \mu \mathrm{m} 2$ ) between cases and controls. The mean villous separation (cases: $188 \mu \mathrm{m}$, controls: $139 \mu \mathrm{m})$ and crypt depth (cases: $237 \mu \mathrm{m}$, control:193 $\mu \mathrm{m}$ ) were significantly larger and mean villous tortuosity was significantly lower (cases:3.04, controls:3.92) in cases. In HIV cases, CD4 counts showed negative correlation with crypt depth $(\mathrm{r}=-0.524)$, villous area $(\mathrm{r}=-0.228)$, villous separation ( $\mathrm{r}=-$ $0.276)$ and positive correlation with villous tortuosity $(\mathrm{r}=0.297)$ in contrast to villous length $(\mathrm{r}=-0.012)$.

Conclusion: Villous tortuosity was significantly reduced in the HIV cases; unlike villous length and villous area. Due to larger villous separation in HIV cases, villous surface area is likely to be lowered and hampered nutrient absorption. Crypt depth increased significantly in HIV positive cases and exhibited the best correlation with CD4 counts.
\end{abstract}

Keywords: HIV, Enteropathy, Villous Morphometry, Crypt Depth, CD4 counts

\section{Introduction}

Chronic diarrhea, malabsorption and weight loss are frequently observed in the human immunodeficiency virus (HIV) positive/AIDS cases $^{[1-3]}$. Several pathogenic mechanisms have been identified or hypothesized as causing diarrhea in HIV-infected individuals, including decreased mucosal surface area, altered secretion of inflammatory mediators, destruction of intestinal mucosa and opportunistic infections due to the lack of an immune reaction ${ }^{[4,5]}$. A reduction in villous surface area and increase in crypt length in HIV infected patients had been reported by few studies using image morphometry ${ }^{[6,7]}$. Evaluation of villous features is vital to assess the severity of modification of villous structure in enteropathy cases and to evaluate the effectiveness of a therapy ${ }^{[8-16]}$. Both histological changes and clinical symptoms in HIV infected patients can be resolved by highly active antiretroviral therapy $(\text { HAART })^{[3]}$. A recent study confirmed on the assessment of histological sections, that the crypt structure in HIV cases can be restored by HAART ${ }^{[8]}$. So morphometric evaluation of the intestinal mucosa will help in quantifying the histological changes in HIV infected patients with gastrointestinal (GI) symptoms.
In this study we attempted an objective evaluation of the characteristics of intestinal villi in HIV positive cases presenting with enteropathy using morphometric techniques on hematoxylin \& eosin (H\&E) stained sections. We studied morphometric parameters i.e., villous length, villous area, villous separation, villous tortuosity and crypt depth in jejunal mucosa of HIV patients with enteropathy and compared with the HIV negative controls. Correlations of evaluated morphometric parameters with CD4 counts in peripheral blood taken at the time of biopsy for all cases were also studied. We were unable to find any previous reports of such an objective evaluation in Indian scenario. Though number of HIV patients presenting GI symptoms has decreased in develop countries, in our country patients continue to present with diarrhea. Therefore, study of changes in jejunal mucosa by morphometry as an adjunct to histology helps in evaluation and better planning of therapy.

\section{Methods}

Thirty confirmed HIV positive cases who presented with chronic diarrhea, malabsorption and weight loss being managed at this tertiary care institute during 2013 to 2014 
were included in this study. Endoscopic biopsies ofjejunal mucosa were received for histopathological examination of these cases. Patients, in whom upper gastrointestinal endoscopy was contraindicated and age less than 18 years were excluded from this study. The status of the opportunistic infections in the cases was not investigated in this study. Permission from Institutional Ethical Committee was obtained for this study (Oct 2012). Twenty one numbers of endoscopic biopsies of intestinal mucosa done for other GI symptoms with unknown HIV status received at this centre and had showed normal histology were used as controls.

\section{Histopathological Examination and Villous} Morphometry: H\&E stained histological sections of 5 micron thickness of formalin fixed paraffin embedded tissue of jejunal mucosa were analyzed. Morphometric analysis was performed by using a computerized digital photomicrograph system (Dewinter Optical Inc. with Digi Eye 330 digital photomicrography camera and Biowizard 4.2 Image analysis software). The measuring scale of the image analysis software was properly calibrated. For each sample at least five fields at 100X magnification, having optimal villous details, were recorded for the study[Figure.1A-C]. For each case, at least 15 villi and crypts were assessed. We evaluated villous length and villous area for each villus, crypt length for each well oriented crypt, villous tortuosity in each captured field and villous separation between the each pair of adjacent villi for every sample. The definitions of these parameters are depicted schematically in Figure2. The length of the line traced through the middle of the villus from the crest to the midpoint of its base line was considered as villous length. The area within the villous outer boundary and base line was considered as villous area. Linear distance between the midpoints of the base lines of two adjacent villi was considered as villous separation. Ratio of the total length of outer boundary of well defined villi to the total length of base lines of the villi in a field was considered as villous tortuosity; and an average of all five fields was calculated. All these measurements were carried out using the image analysis software.

Statistical Analysis: SPSS17.0 (Statistical Package for Social Sciences) software programme was used in statistical analysis. Mean values with standard deviation (SD) for each sample of all studied parameters were calculated. Mean values of each parameter was considered as the parameter of the sample. The mean values with SD and range of these parameters were evaluated for both cases and controls. Unpaired Student's t-test was performed and 'p' values were calculated to evaluate significance in difference between the cases and the controls. The Pearson correlation coefficients ' $r$ ' for all pairs of studied parameters for the cases and controls were calculated.

\section{Results}

The mean age at the time of biopsy for the cases was 39 years (range: 26 - 53 years) and comprised of 19 males and 11 females; the mean age for the controls was 42 years (range:18 - 68years) and comprised of 11 males and 10 females. At the time of biopsy, average duration of HIV infection for the cases was 4.5 years (range: 0 - 15 years) and average duration of antiretroviral therapy (ART) was 2.1 years(range: 0-9 years). H\&E stained histological sections with villous atrophy and normal villous found in HIV positive cases are shown in Fig1A\& B respectively; Fig1Cshows mucosa inHIV negative controls. On examination of $\mathrm{H} \& \mathrm{E}$ sections, villous atrophy of varying degrees was found in most of theHIV positive cases. Few cases showed almost normal villi with mild inflammatory infiltrate; while some showed mild abnormalities. The enterocytes were normal; mild increase in lymphocytic inflammatory infiltrate in the lamina propria was seen in some of the cases. No granulomas, dysplasia or evidence of malignancy were found.

Evaluated morphometric parameters of the cases and controls are shown inFigure3(A-E). These figures represent the box plots of villous length, villous area, villous separation, villous tortuosity and crypt depth for the both groups. The mean values of the studied parameters with standard deviation (SD) and range for cases and controls are presented in the table 1 . The $\mathrm{p}$ values to predict the difference of each pair of these two groups for all the parameters are also presented in this table. There was no significant difference in the villous length between HIV cases and controls $(\mathrm{p}=0.9858)$. Though, the mean villous area in cases $\left(30905 \mu \mathrm{m}^{2}\right)$ was higher than the controls $\left(25864 \mu \mathrm{m}^{2}\right)$, the difference was not statistically significant $(\mathrm{p}=0.0610)$. The mean villous separation in cases $(188 \mu \mathrm{m})$ was significantly higher than the controls $(139 \mu \mathrm{m})$. The mean villous tortuosity in cases (3.04) was significantly lower than the controls (3.92). The mean crypt depth in cases $(237 \mu \mathrm{m})$ was significantly greater than the controls $(193 \mu \mathrm{m})$.

\section{Correlation of Studied Parameters}

HIV cases: Pearson correlation coefficients between each pair of studied parameters analyzed for $30 \mathrm{HIV}$ positive cases are shown in the Table2. Crypt depth showed significant positive correlation with villous length $(\mathrm{r}=0.504)$ and villous area $(\mathrm{r}=0.588)$. Villous length showed strong positive correlation with villous area $(\mathrm{r}=0.710)$ and villous 
tortuosity showed significant negative correlation with villous separation $(r=-0.478)$.

Controls: Pearson correlation coefficients between each pair of studied parameters analyzed for $21 \mathrm{HIV}$ negative controls are shown in the Table3. Crypt depth showed mild negative correlation with villous length $(\mathrm{r}=-0.386)$; did not show meaningful correlation with other parameters. Villous length showed significant positive correlations with villous area $(r=0.682)$ and villous tortuosity $(\mathrm{r}=0.455)$. Villous separation showed significant positive correlation with villous area $(\mathrm{r}=0.526)$ and negative correlation with villous tortuosity $(\mathrm{r}=-0.482)$.
Correlation of CD4 Counts with Morphometric Parameters: The mean value of CD4 counts of the cases was $333 \mathrm{~mm}^{-3}$ (range: $24-1048 \mathrm{~mm}^{-3}$ ). Scatter plots of villous length, villous area, villous separation, villous tortuosity and crypt depth versus CD4 counts for the all HIV positive cases with linear regressions are presented in Figure4(A-E). CD4 counts showed weak negative correlation with villous area $(\mathrm{r}=-0.228)$, mild negative correlation with villous separation $(\mathrm{r}=-0.275)$, moderate negative correlation with crypt depth $(\mathrm{r}=-0.524)$ and mild positive correlation with villous tortuosity $(\mathrm{r}=0.295)$. Whereas, villous length $(\mathrm{r}=-0.012)$ showed no meaningful correlation with $\mathrm{CD} 4$ counts.

Table: 1 Mean values with SD and range of the studied parameters of 30 cases and 21 controls with $p$ values.

\begin{tabular}{|c|c|c|c|c|}
\hline SI No. & Parameters (unit) & $\begin{array}{c}\text { Cases }(n=30) \\
\text { Male }=19, \text { Female }=11\end{array}$ & $\begin{array}{c}\text { Controls }(n=21) \text { Male=11, } \\
\text { Female }=10\end{array}$ & $p$ value \\
\hline 1 & Villous length $(\mu \mathrm{m})$ & $\begin{array}{c}269 \pm 53 \\
(180-379)\end{array}$ & $\begin{array}{c}270 \pm 62 \\
(176-408)\end{array}$ & 0.9858 \\
\hline 2 & Villous area $\left(\mu m^{2}\right)$ & $\begin{array}{l}30905 \pm 10192 \\
(16259-57866)\end{array}$ & $\begin{array}{c}25864 \pm 7653 \\
(9680-41396)\end{array}$ & 0.0610 \\
\hline 3 & Villous separation $(\mu \mathrm{m})$ & $\begin{array}{c}188 \pm 26 \\
(148-251)\end{array}$ & $\begin{array}{c}139 \pm 23 \\
(88-179)\end{array}$ & $<0.0001^{*}$ \\
\hline 4 & Villous tortuosity & $\begin{array}{c}3.04 \pm 0.41 \\
(2.26-3.90) \\
\end{array}$ & $\begin{array}{c}3.92 \pm 0.81 \\
(2.53-5.40)\end{array}$ & $<0.0001^{*}$ \\
\hline 5 & Crypt depth $(\mu \mathrm{m})$ & $\begin{array}{c}237 \pm 43 \\
(139-270)\end{array}$ & $\begin{array}{c}193 \pm 38 \\
(139-270)\end{array}$ & $0.0004^{*}$ \\
\hline 6 & CD4 counts $\left(\mathrm{mm}^{-3}\right)$ & $\begin{array}{l}333 \pm 270 \\
(24-1048)\end{array}$ & Not available & - \\
\hline
\end{tabular}

Table2: Correlations between each pair of studied parameters: $30 \mathrm{HIV}$ positive cases.

\begin{tabular}{|l|c|c|c|c|c|c|}
\hline & Crypt depth & Villous length & Villous area & Villous separation & Villous tortuosity & CD4 Counts \\
\hline Crypt depth & 1.000 & & & & & \\
\hline Villous length & $0.504^{* *}$ & 1.000 & & & & \\
\hline Villous area & $0.588^{* *}$ & $0.710^{* *}$ & 1.000 & & & \\
\hline Villous separation & 0.275 & 0.194 & 0.327 & 1.000 & & \\
\hline Villous tortuosity & -0.279 & -0.010 & 0.105 & $-0.478^{* *}$ & 1.000 & 0.297 \\
\hline CD4 Counts & $-0.524^{* *}$ & -0.012 & -0.228 & -0.276 & 1.000 \\
\hline 2-tailed Pearson 'r'. * $p<0.05,{ }^{* *} p<0.01$. & & & \\
\hline
\end{tabular}

Table3:Correlations between each pair of measured parameters: $21 \mathrm{HIV}$ negative controls.

\begin{tabular}{|l|c|c|c|c|c|}
\hline & Crypt depth & Villous length & Villous area & Villous separation & Villous tortuosity \\
\hline Crypt depth & 1.000 & & & & \\
\hline Villous length & -0.386 & 1.000 & & & \\
\hline Villous area & -0.048 & $0.682^{* *}$ & 1.000 & & \\
\hline Villous separation & 0.161 & 0.132 & $0.526^{*}$ & 1.000 & \\
\hline Villous tortuosity & -0.017 & $0.455^{*}$ & 0.184 & $-0.482^{*}$ & 1.000 \\
\hline 2-tailed Pearson ' $r$ '. ${ }^{*} p<0.05,{ }^{* *} p<0.01$.
\end{tabular}



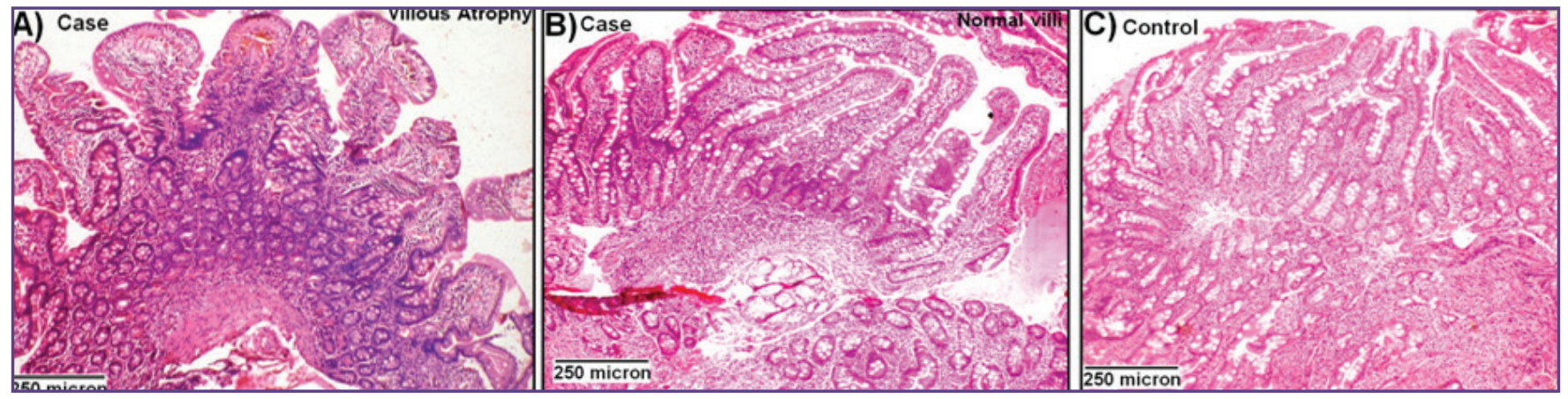

Fig. 1(A-C): Images of H\&E stained histological sections used for morphometric evaluation of parameters:(A)villous atrophy and (B) almost normal villusin HIV infected cases; and (C) HIV negative control. Original magnification is 100X and the scale put in the images.

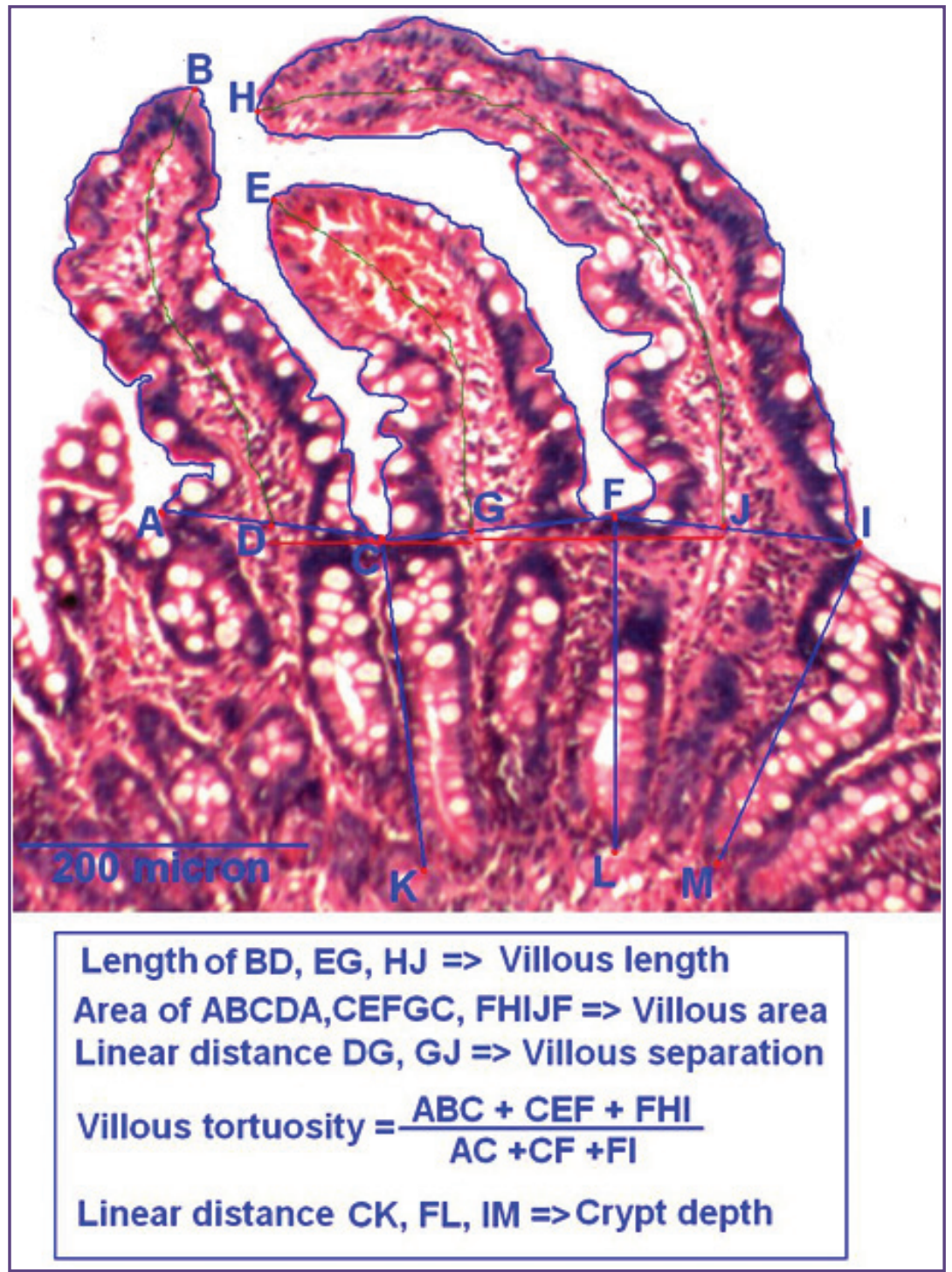

Fig. 2: Measurement scheme of studied parameters: villous length, villous area, villous separation, villous tortuosity and crypt depth. 


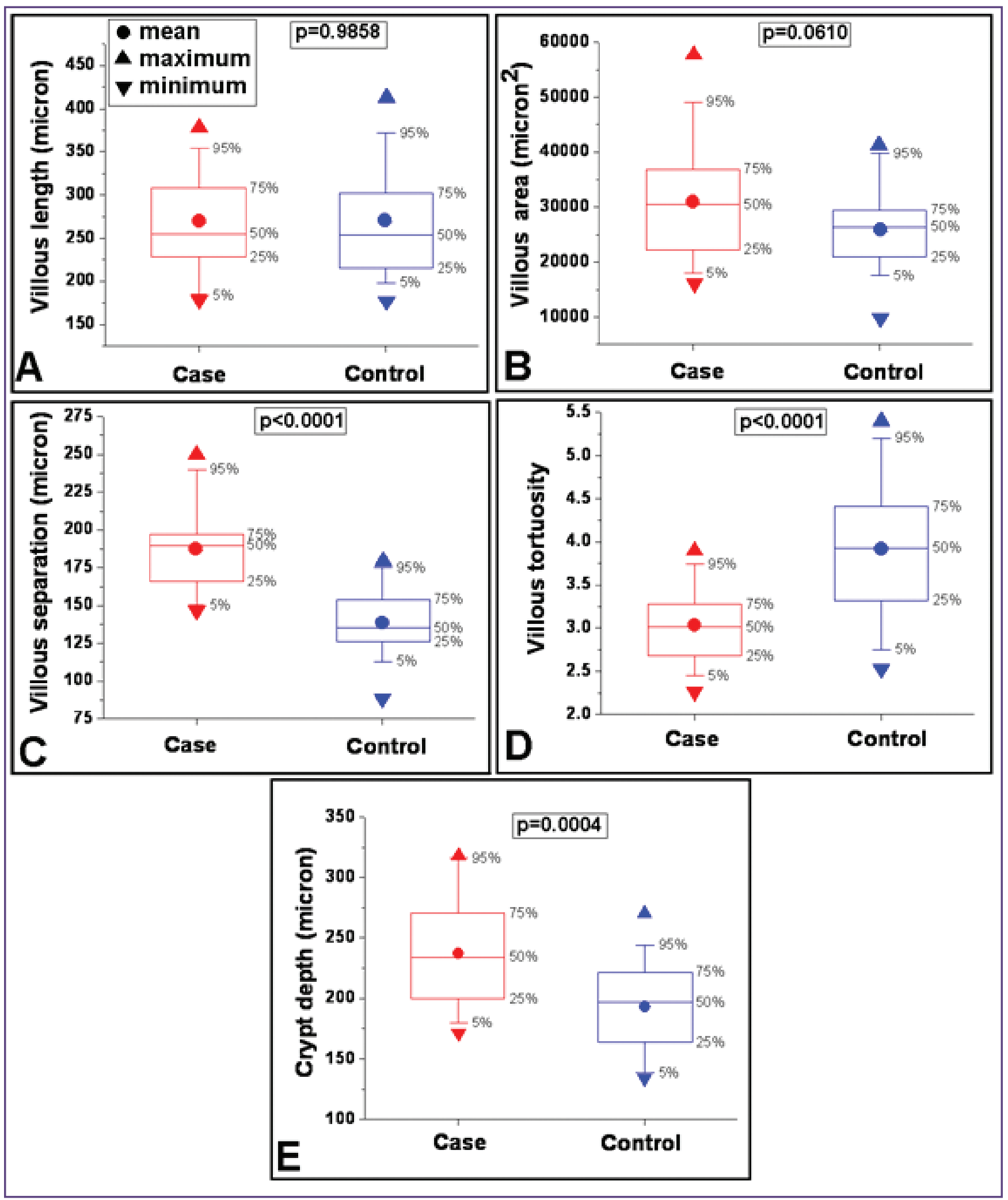

Fig. 3(A-E): Box plots of cases and controls with p value of t-test between them for: (A) villous length, (B) villous area, (C) villous separation, (D) villous tortuosity and (E) crypt depth. 


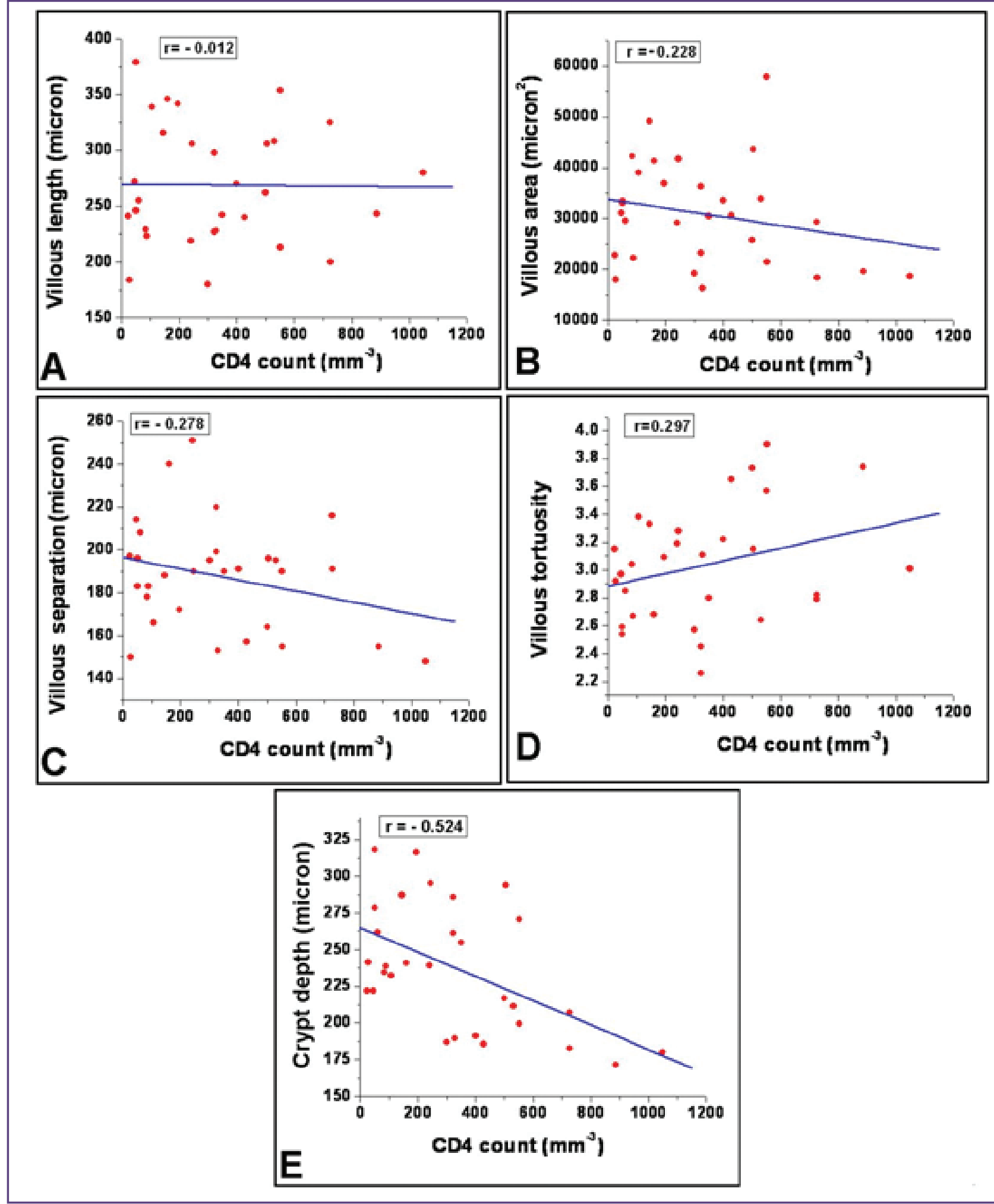

Fig. 4(A-E): Scatter plots of CD4 count with (A) villous length, (B) villous area, (C) villous separation, (D) villous tortuosity and (E) crypt depth of the 30 HIV positive cases. Linear regression between these parameters and CD4 count are shown by the solid linesand Pearson correlation coefficient ' $r$ ' were shown in respective plot. 


\section{Discussion}

Histological changes of the gastrointestinal mucosa and opportunistic infections due to the decrease of immunity are commonly observed in HIV positive cases ${ }^{[1-6]}$. Increased levels of inflammation and decreased levels of mucosal repair and regeneration have been seen in enteropathy with HIV infection ${ }^{[17]}$. Reduction of villous surface area and increased crypt depth with less mitotic figures was observed in HIV patients with gastrointestinal complaints compared to the controls by Ullrich et a ${ }^{[5]}$. Batman et al reported that infection of cells in the lamina propria of the jejunum stimulates an increase in crypt length and a fall in villous surface area in HIV patients ${ }^{[6]}$. Villous atrophy and flatness indicates reduction of villous surface area in the intestine, through which nutrients are absorbed. This reduction of villous surface area decreases transportation rate of nutrients through the villi which may leads to malabsorption and weight loss. A quantitative assessment of the villi and crypts and their comparison with suitable controls gives a greater perception about such disease conditions. Correlations of these parameters with CD4 counts provide important information about disease progression. Many researchers have studied the histological changes in villous structure in cases of HIV with enteropathy; however few quantitative studies using image morphometry on villous alterations have been reported ${ }^{[5-14]}$. Morphometry is a useful tool to assess the effectiveness of a treatment by quantifying histological abnormalities in enteropathy ${ }^{[8,16]}$.

Significant increase in crypt depth was found inthe HIV positive cases compared to the controls in our study; like previous research ${ }^{[5]}$. No significant difference of mean villous length was found between HIV infected cases and controls in our study. We also observed that, crypt depth showed positive correlation with villous length in HIV positive cases; but negative correlation in controls.

The villous area is related to its volume in three dimensional scenarios; though its mean value was larger in cases than the controls, but difference was not significant. Kelly et al also reported that mean villous area, which was called villous compartmental volume by them, were $16659 \mu \mathrm{m}^{2}$ in HIV seronegative controls, $16733 \mu \mathrm{m}^{2}$ and $18195 \mu \mathrm{m}^{2}$ in HIV seropositive cases with CD4 count $\geq 200 \mathrm{~mm}^{-3}$ and $<200 \mathrm{~mm}^{-3}$ respectively, and the differences were not significant [13]. Though our findings in this respect were similar to their study, the size of the villous found by us was larger for studied samples. The disparity might arise due to the geographical variation of populations or difference in choosing the region/criteria of villi for size evaluation or measurement techniques.

The inverse of villous separation gives a measure of villous concentration. In HIV cases the mean of villous separation was found significantly larger than the controls. This translates that the villous concentration decreases in such cases. Decrease in repair and regenerating ability of villous in such condition leads to the lower villous concentration.

In our study we defined a parameter named villous tortuosity, which was the ratio of total length of outer boundary of well defined villi to the total length of base lines of the villi in a field. Villous tortuosity is related to the villous surface area per unit area of mascularis mucosa in three dimensional scenario. Higher villous tortuosity is likely to have more villous surface area in intestine. In this study we found that mean villous tortuosity was significantly reduced in the HIV cases than the controls. Hence, total villous surface area is to be expected to decrease in HIV cases, which contributes towards the reduction of rate of diffusion of nutrients through the intestine and leads to malabsorption. Kelly et al also reported that mean value of epithelial surface area was larger in HIV seronegative controls than the HIV positive cases ${ }^{[13]}$.

Peripheral blood CD4 counts have been used for monitoring HIV patients and deciding antimicrobial prophylaxis and antiretroviral therapy ${ }^{[17-18]}$. HIV infection leads to loss of CD4 T-cells and the risk of complications, especially potentially lethal opportunistic infections increase with the decline of this count ${ }^{[18-19]}$.In our study, we found that the meanCD4 count was $333 \mathrm{~mm}^{-3}$ (median $311 \mathrm{~mm}^{-3}$ )in the HIV cases and correlated CD4 count with the evaluated villous morphometric parameters. CD4 counts in controls of our study were not recorded. We found that villous length did not show any meaning full correlation with the CD4 counts. Villous area showed a weak negative correlation with the CD4 counts; i.e. possibility of finding a larger villous is slightly more when CD4 counts decrease. This result supported the finding of larger mean villous area in cases than in the controls.

Villous separation showed mild negative correlation with the CD4 counts. It suggests that the villi are far from each other and have lower villous density when CD4 count decreases. Similarly, villous tortuosity demonstrated mild positive correlation with the CD4 counts. It hints that the villous surface area, through which nutrients are transported, increases with the enhancement of CD4 
counts. Crypt depth, which is related to crypt hyperplasia, showed moderate negative correlation with the CD4 counts. It suggests that the crypt hyperplasia may be resolved with improvingCD4 counts.

A recent study has showed that using HAART treatment in HIV patient was able to restore the crypt structure ${ }^{[8]}$. In this study we observed that, the differences of villous structure and crypt depth in HIV cases in comparison to controls increase with decline of CD4 counts. Among the all morphometric parameters, crypt depth showed the best correlation with the CD4 counts. Small sample size and unknown HIV status of the controls were the limitations of this study.

\section{Conclusion}

Quantitative assessments of crypts and villi provide a greater understanding about disease progression and patients' outcome in cases of HIV with enteropathy. Crypt depth increased significantly in HIV cases and showed negative correlation with CD4 counts. Villous separation was significantly larger and villous tortuosity was significantly smaller in HIV cases than the controls. Villous tortuosity showed weak positive correlation with villous length and moderate negative correlation villous separation. Villous area showed weak and villous separation showed mild negative correlations of CD4 counts of HIV cases. Crypt depth and villous tortuosity are better parameters for the morphometric assessment of enteropathy in HIV positive cases.

\section{Acknowledgements}

Authors acknowledge Professor and Head, Department of Internal Medicine and Professor and Head, Department of Pathology of the institute performing this study for their overall support to complete it.

\section{Conflict of Interest}

We declare that we have no conflict of interest.

\section{Reference}

1. Sharpstone D, Gazzard B. Gastrointestinal manifestations of HIV infection. Lancet 1996;348:379-83.

2. Owens SR, Greenson JK. The pathology of malabsorption: current concepts. Histopathology 2007; 50: 64-82.

3. Bhaijee F, Subramony C,Tang S, Pepper DJ. Human Immunodeficiency Virus Associated GastrointestinalDisease: Common Endoscopic Biopsy Diagnoses. Pathology Research International 2011; Article ID 247923, doi:10.4061/2011/247923.
4. Kotler DP, Giang TT, Thiim M, Nataro JP, Sordillo EM , Orenstein JM,et al. Chronic bacterial enteropathy in patients with AIDS. J Infect Dis1995;171:552-558.

5. Ullrich R, Zeitz M, Heise W, L'age M, Hofken G, Riecken EO. Small intestinal structure and function in patients infected with Human Immunodeficiency Virus: evidence for HIV-induced enteropathy. Ann Intern Med 1989; 111: 15-21.

6. Batman PA, Kapembwa MS, Miller ARO, Sedgwick PM, Lucas S, Sewankambo NK,et al.HIV enteropathy: comparative morphometry of the jejunal mucosa of HIV infected patients resident in the United Kingdom and Uganda. Gut 1998;43:350-355.

7. Cummins AG, LaBrooy JT, Stanley DP, Rowland R, Shearman DJC. Quantitative histological study of enteropathy associated with HIV infection. Gut1990;31:317-321.

8. Batman PA, Kapembwa MS, Belmonte L, Tudor G, Kotler DP, Potten CS et al. HIV enteropathy: HAART reduces HIVinduced stem cell hyperproliferation and crypt hypertrophy to normal in jejunal mucosa. J Clin Pathol 2014;67:14-18.

9. Batman PA, Miller AR0, Forster SM, Harris JRW, Pinching AJ, Griffin GE. Jejunal enteropathy associated with human Immunodeficiency virus infection: quantitative histology. J Clin Pathol 1989;42:275-281.

10. Keating J, Bjarnason I, Somasundaram S, Macpherson A, Francis N, Price AB et al. Intestinal absorptive capacity, intestinal permeability and jejunal histology in HIV and their relation to diarrhea. Gut 1995; 37: 623-629.

11. Kelly P, Davies SE, Mandanda B, Veitch A, McPhail G, Zulu I, et al. Enteropathy in Zambians with HIV related diarrhea: regression modeling of potential determinants of mucosal damage. Gut1997; 41: 811-816.

12. Pires ALG, da Silveira TR, da Silva VD. Digital morphometric and stereologic analysis of small intestinal mucosa in well-nourished and malnourished children with persistent diarrhea. J Pediatr (Rio J) 2003; 79:329-336.

13. Kelly P, Menzies I, Crane R, Zulu I, Nickols C, Feakins R etal. Responses of small intestinal architecture and function over time to environmental factors in a tropical population. Am J Trop Med Hyg2004; 70: 412-419.

14. Batmana PA, Kotlerb DP, Kapembwac MS, Boothd D, Pottend CS, Orenstein J M et al. HIV enteropathy: crypt stem and transit cell hyperproliferation induces villous atrophy in HIV/Microsporidia-infected jejunal mucosa. AIDS 2007; 21:433-439.

15. Cummins AG, Alexander BG, Chung A, Teo E, Woenig JA, Field JB, et al. Morphometric Evaluation of Duodenal Biopsies inCeliac Disease. Am J Gastroenterol 2011; 106:145-150.

16. Louis-Auguste J, Greenwald S, Simuyandi M, Soko R, Banda R and Kelly Paul. High dose multiple micronutrient supplementation improves villous morphology in 
environmental enteropathy without HIV enteropathy: results from a double-blind randomised placebo controlled trial in Zambian adults. BMC Gastroenterology 2014;14(15):1-10.

17. Brenchley JM, Douek DC. HIV infection and the gastrointestinal immuneSystem.MucosalImmunology2008; 1:1:23-30.

18. Maini M K, Gilson RJC, Chavda N, Gill S, Fakoya A, Ross EJ et al. Reference ranges and sources of variability of CD4 counts in HIV-seronegative women and men. Genitourin Med 1996;72:27-31.

19. Anukam KC, OsazuwaEO, Osadolor HB, Bruce AW and Reid GR, Yogurt Containing Probiotic Lactobacillus rhamnosus GR-1and L. reuteri RC-14 Helps Resolve Moderate Diarrheaand Increases CD4 Count in HIV/AIDS Patients. J Clin Gastroenterol2008; 42:239-243.

*Corresponding author:

Dr. Dibyajyoti Boruah, Scientist-'D’ Department of Pathology, Armed Forces Medical College, Pune - 411040, Maharashtra, INDIA

Phone: +919823553654, Fax : +91-20-26331776

Email: dibyajyotibh@yahoo.co.uk

Date of Submission : 01.02.2017

Date of Acceptance : 17.04.2017

Financial or other Competing Interests: None.

Date of Publication : 31.08.2017 